\title{
MODAL AND STRUCTURAL IDENTIFICATION OF A MULTI-SPAN MASONRY ARCH BRIDGE
}

\author{
PAOLO BORLENGHI ${ }^{1 *}$, ANTONELLA SAISI ${ }^{1}$ AND CARMELO GENTILE $^{1}$ \\ ${ }^{1}$ Department of Architecture, Built environment and Construction engineering (DABC) \\ Politecnico di Milano, Milan, Italy \\ Piazza Leonardo da Vinci, 32 - 20133 Milan, Italy \\ e-mail: \{paolo.borlenghi, antonella.saisi, carmelo.gentile\}@polimi.it (*corresponding author)
}

Keywords: Masonry bridges, Ambient vibration tests, FE model updating, Non-Destructive Inspections

\begin{abstract}
The Olla bridge is a multi-span masonry arch bridge dating back to the second half of the $19^{\text {th }}$ century. The bridge is $117 \mathrm{~m}$ long and includes five arches of different spans. Since no original drawings or blueprints of the bridge were found in the archives, the missing information on the geometry of the structure were retrieved through a geomatic survey, whereas the unknown structural details were assumed according to historical handbooks and similar projects. In addition, limited material samples were taken to solve typical uncertainties such as the effective thickness of arches. Subsequently, ambient vibration tests were performed, and different output-only techniques were applied to the acquired time series with the two-fold objective of identifying the dynamic characteristics of the bridge and roughly verifying the invariance of the modal parameters. Finally, all the available information were summarised in a Finite Element model, that - after the updating of uncertain parameters - turned out to be capable of reproducing the identified dynamic characteristics of the structure with a high level of accuracy.
\end{abstract}

\section{INTRODUCTION}

The development of the rail transport in the $19^{\text {th }}$ century involved the construction of a large number of masonry arch bridges giving impulse to the improvement of this structural typology. Consequently, masonry arch bridges were the dominant technology in bridge design until the first half of the $20^{\text {th }}$ century, when reinforced concrete progressively replaced brick and stone masonry. Nevertheless, many masonry bridges are still in use today and they represent essential infrastructures for the European road and railway networks. In recent years, due to their key role and uncertain state of preservation, masonry bridges have received increasing attention from the scientific community, resulting in a series of experimental investigations and numerical studies (see e.g. [1-3]). Furthermore, as all historical constructions, masonry bridges are affected by numerous uncertainties related to material properties and construction details: when neither the original blueprints nor the documentations on repairs and interventions are available, extensive experimental surveys are needed to retrieve the actual internal morphology of the bridge (i.e. backing arrangement or effective thickness of arches). 
In this context, documentary research and limited material tests, together with Operational Modal Analysis (OMA) and Finite Element Model Updating (FEMU), can be applied to reduce uncertainties and contribute in establishing a reliable numerical model. The paper summarises the investigations carried out on the Olla bridge, involving the following steps: (i) documentary research, (ii) geomatic survey, (iii) minor destructive and ambient vibration tests and (iv) FE modelling and updating.

\section{THE OLLA BRIDGE}

The Olla bridge (Ponte dell'Olla in Italian, Fig. 1a) is a multi-span masonry arch bridge built in the second half of the $19^{\text {th }}$ century over the Stura river. It carries the State Route no. 21 (SS21, i.e. the roadway connecting the city of Cuneo with the French border) between the municipalities of Gaiola and Borgo San Dalmazzo in the northwest part of Piedmont, Italy. Due to its localisation, the bridge has a strategic role for the economy of the area since it is the only entry to the Stura di Demonte Valley for trucks and commercial vehicles.

The strueture is approximately $117 \mathrm{~m}$ long and has a maximum height over the river of about $42 \mathrm{~m}$. It is composed of five masonry arches, symmetrically distributed, with spans of 10,20 , and $25 \mathrm{~m}$, respectively. Piers and abutments are in a good quality ashlar stone masonry while arches and spandrel walls are in brick masonry. The documentary research started in the archive of the local Authority that was responsible for the design (the Genio Civile) but the original drawings were not found. Therefore, various construction details on the internal morphology of the structure were initially assumed according to historical construction
handbooks and then eventually modified in establishing the FE model.
2.1 Geometry survey
In order to obtain complete representation of the existing structure, a topographic survey was performed in September 2018 [4] using a total station (Leica TCRA 1203) and a laser

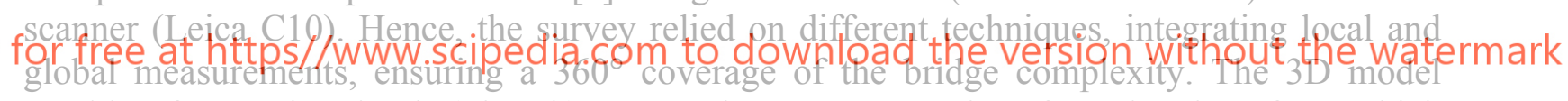
resulting from point clouds (Fig. 1b) was used to extract a series of 2D drawings from which the FE model was developed. It is worth noting that once a point cloud is available, it is possible to extract an unlimited number of $2 \mathrm{D}$ sections for future applications.

(a)

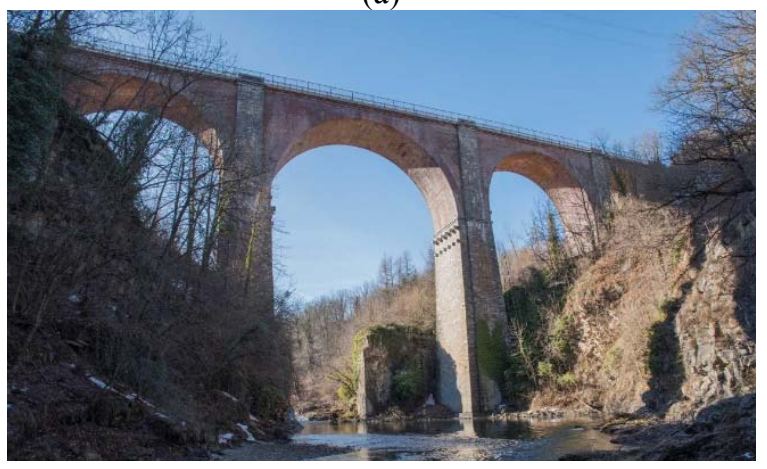

(b)

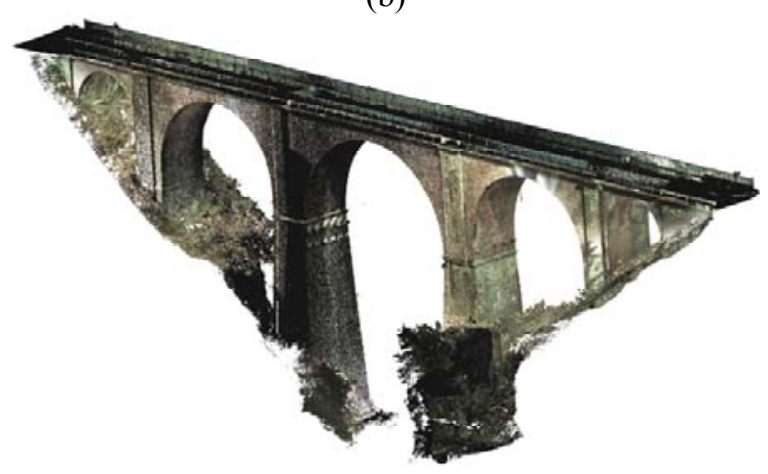

Figure 1: The Olla bridge: (a) View from the Stura river; (b) 3D model from the geomatic survey [4]. 


\subsection{Historical background}

Firstly, the historical analysis focused on the research of the original blueprint of the Olla bridge at the State Archive of Cuneo: unlikely, this first phase did not bring to any result. Consequently, the focus moved to the general history of the roadway to which the bridge belongs, examining the maintenance reports of the Ministry of Public Works [5] and the history of a tramway that was passing on the bridge in the first half of the $20^{\text {th }}$ century [6].

The first record regarding the existence of a bridge called "Olla", between the small towns of Gaiola and Borgo San Dalmazzo, dates back to the $18^{\text {th }}$ century. In that period and for one more century, the main route from the valley to the city of Cuneo was not crossing the river, so that the bridge served just as a secondary connection. In 1857 [5] - a few years before the proclamation of the Italian Kingdom - the road between Borgo San Dalmazzo and the French border was declared of national importance and a large project of renovation started, involving the construction of a new Olla bridge. The new structure was completed in 1887 [5] shortening the road and removing the difference in altitude caused by the older single-span masonry bridge (Fig. 2a). The design was carried out by the local chief engineer of the Italian Royal Corps of Genio Civile (public works office), Giovanni Delfino [6].

In 1912 the construction of a steam tramway between Borgo San Dalmazzo and the Stura valley was approved by the National Authority, completing the existing part that was starting from Cuneo [6]. The rails were installed in the downstream side of the bridge deck, and the tramline worked until 1948 [6], with some interruptions during the war periods.

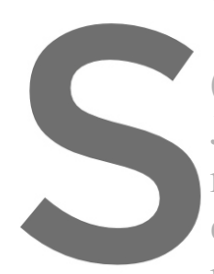

During the Second

(Figs. $2 \mathrm{~b}$ and 3 ): accordin

July $13^{\text {th }}, 1944$ to is 19

repaired starting from September 1945

execution of the intervention. Regarding the

remains of the abutments are still visible nowadays (Fig. 1a).
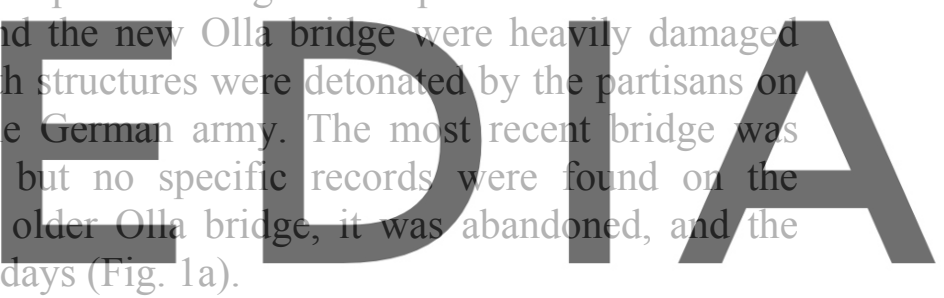

In conclusion, the documentary research revealed the construction period and the Authority

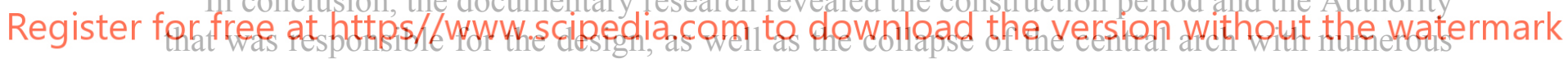

historical pictures. Nevertheless, a large number of missing information regarding the structurai details remain unsolved.

(a)

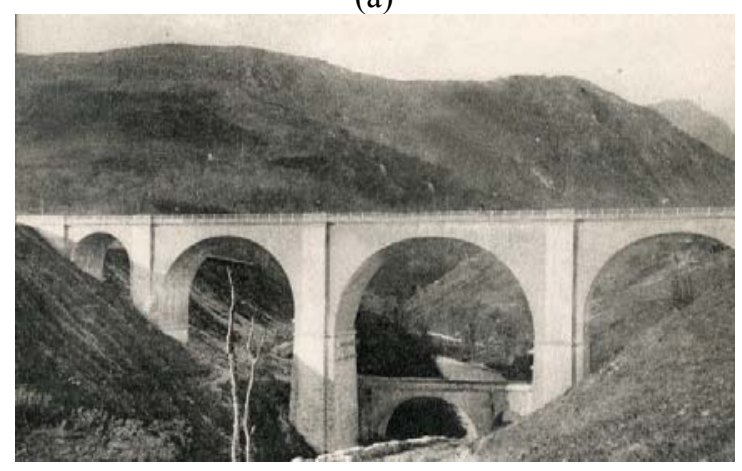

(b)

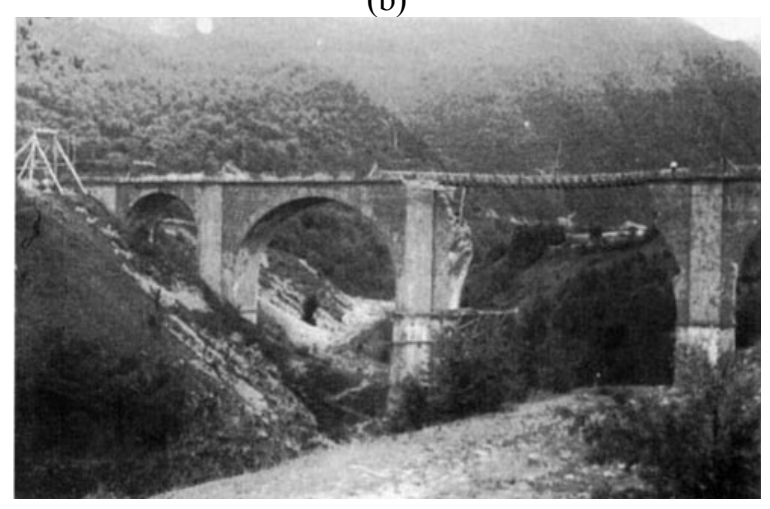

Figure 2: Historical views of the investigated structure before (a) and after (b) the damages of 1944 [6]. 
(a)
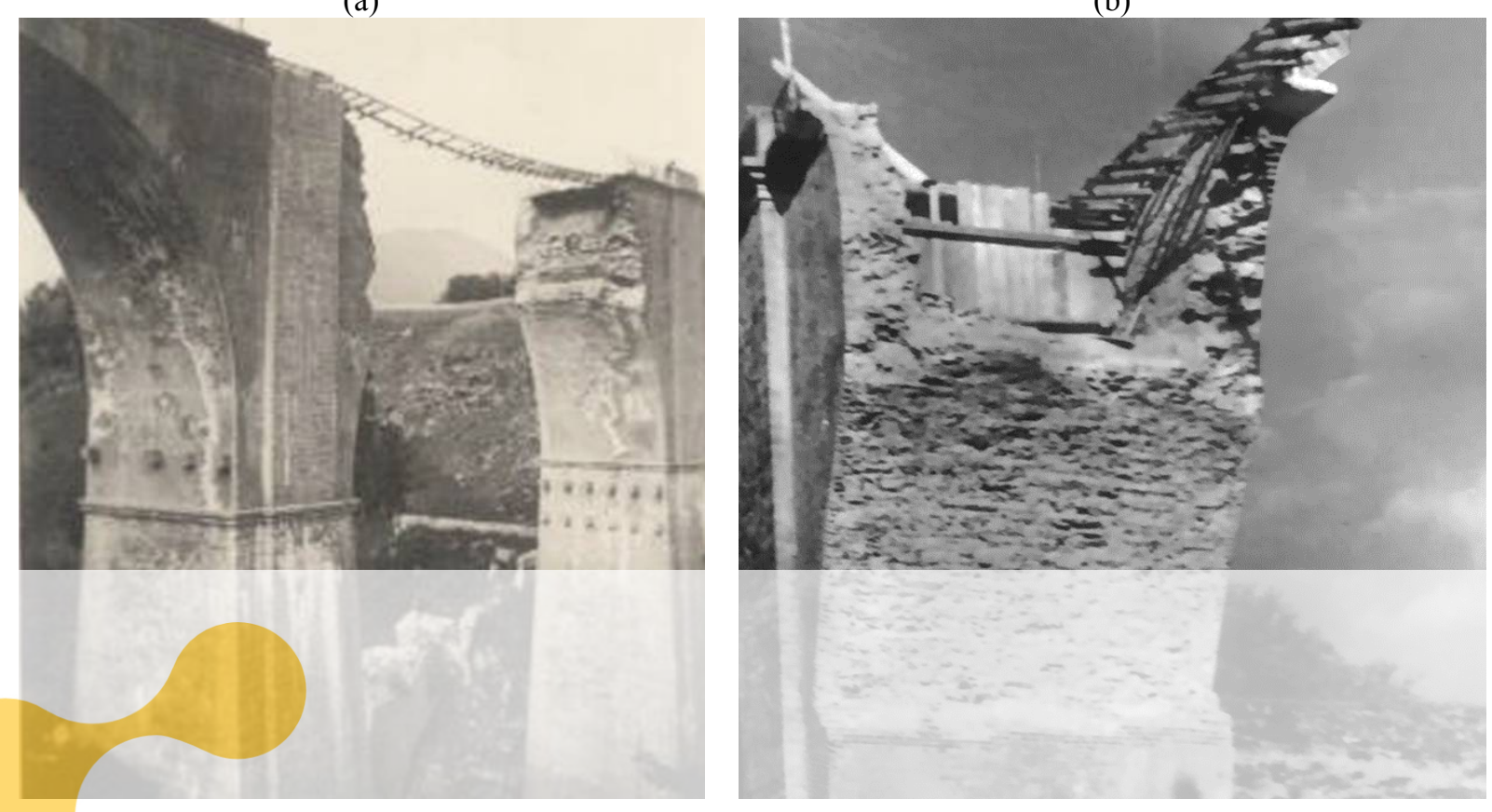

Figure 3: Views of the damages occurred in 1944, before (a) and after (b) the complete detachment of the collapsed arch.

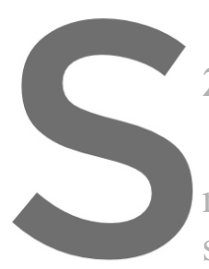

2.3 Structural details and intermal morphology
Evaluating the contribution of backing and spandrel walls to the load-bearing catpan
masonry bridge is often a complex task. The structural role of these elements
substantially according to thei geometric arrangement and material characteristics.

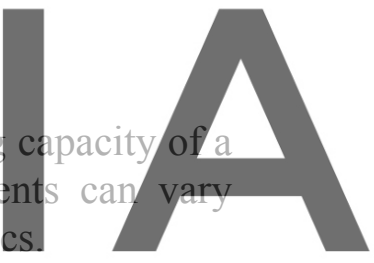

To overcome the missing knowledge on structural details and internal morphology, the

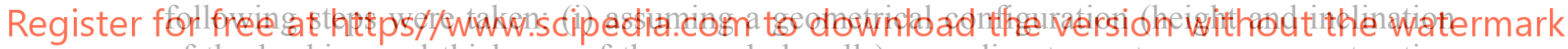
of the backing and thickness of the spandrel walls) according to contemporary construction

handbooks and similar projects, (ii) verifying some of those assumptions with a limited number of coring tests, and (iii) including the material property of the backing among the updating parameters in the FEMU procedure.

In the case of Olla bridge, the well-known construction handbook of Curioni [7], published in 1873, and the projects of masonry viaducts published on the Journal of Public Works (Giornale del Genio Civile [8]) were adopted as reference. This choice was motivated by both the time of publication and the geographical proximity, suggesting a remarkable affinity with the investigated bridge. Generally, when the distance between the arch and the deck was quite high, the thickness of the spandrels had a variable section, wider near the arch [7]. In addition, the height of the backing - in the pier axis - was equal to $2 / 3$ of the arch radius [7] but it can variate considerably according to the designer. Fig. 4 shows two examples of masonry viaducts published in [8] with a backing height almost equal to arch radius.

Furthermore, from the historical pictures taken after the collapse of the central arch (Fig. 3) it is possible to verify the presence of a solid backing that prevented the overturning of the central piers from the unbalanced trusts coming from the lateral arches (both with spans equal to $20 \mathrm{~m}$ ). Regarding the collapse mechanism, it is worth noting that: (i) at first the arch did not 
collapse in the ideal skewback at the end of the pier (Fig. 3a), while (ii) subsequently the remaining part of the arch on the Gaiola side collapsed separately in respect to the backing (Fig. 3b). These observations underline the importance of better understanding the role of backing and spandrels in the structural response of the Olla bridge.

(a)

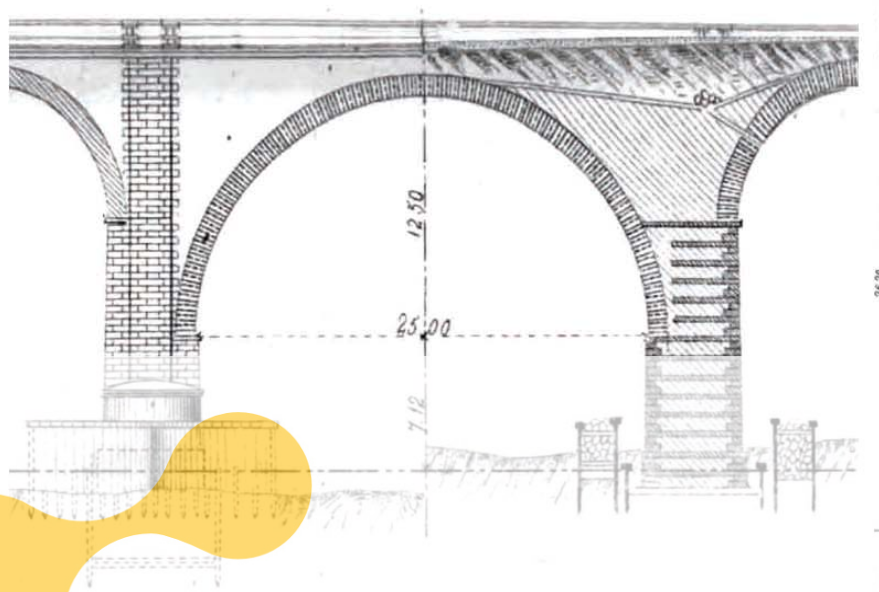

(b)

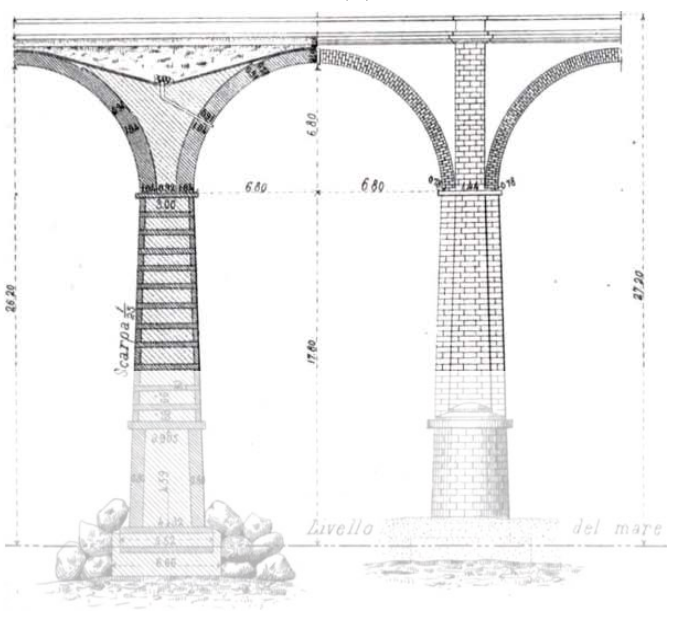

Figure 4: Historical drawings (1879) of the railway viaducts of Zoagli (a) and Sori (b) [8].
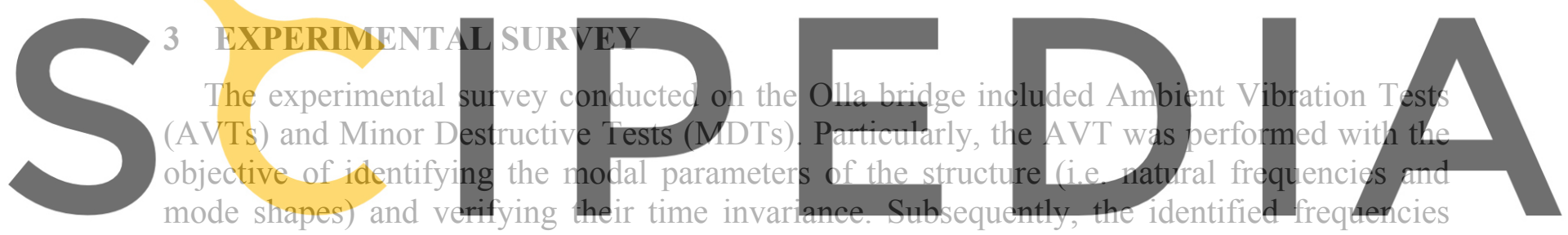

were used to correct the numerical model of the bridge within a FEMU procedure. The MDTs

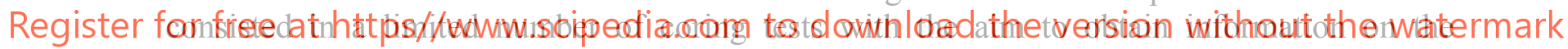
effective thickness of arches and spandrels and material type for the fill. Due to the limited extension of the core drill machine, no information on the backing was obtained.

\subsection{Ambient vibration tests and modal identification}

The AVT was conducted on July $31^{\text {st }}$, 2018 with one lane open to traffic; the acceleration responses of the bridge were measured in 11 selected points belonging to the downstream side of the deck. As represented in Fig. 5a, the sensor layout was designed to guarantee a complete representation of the lateral mode shapes (11 transversal sensors), and a partial reconstruction of vertical and longitudinal ones, deploying 3 vertical sensors placed in the centre of the major arches, where the maximum modal displacements were expected.

During the test the following devices were used: (a) an acquisition laptop; (b) a multichannel acquisition system with 4 NI9234 modules (24-bit resolution, $102 \mathrm{~dB}$ dynamic range and anti-aliasing filters); (c) $14 \mathrm{WR} 731 \mathrm{~A}$ piezoelectric accelerometers $(10 \mathrm{~V} / \mathrm{g}$ sensitivity and \pm 0.50 g of peak acceleration); (d) 14 power unit amplifiers (WR P31). The amplifiers were aimed at enhancing the performance of the acquisition chain, providing a constant current to power the internal amplifier, signal amplification and selective filtering. The sampling 
frequency adopted was equal to $200 \mathrm{~Hz}$, which is more than enough for the considered structure whose dominant frequencies are below $10 \mathrm{~Hz}$. Therefore, low pass filtering and decimation were applied to down-sample the data to $40 \mathrm{~Hz}$, obtaining a Nyquist frequency of $20 \mathrm{~Hz}$. The acquired data were then divided in 4 dataset of $2400 \mathrm{~s}$ to verity the invariance of the identified modal parameters over the testing time.

The extraction of the modal parameters was performed by applying three well-known algorithms: the Frequency Domain Decomposition (FDD [9]), the data-driven Stochastic Subspace Identification (SSI-data [10]) and the Covariance-based Stochastic Subspace Identification (SSI-Cov [10]). The first two techniques are available in the commercial software ARTeMIS [11] whereas the third one was developed in a previous research [12].

Overall, 5 lateral and 3 vertical vibration modes are identified in the frequency range of 0 $10 \mathrm{~Hz}$. Figure $5 \mathrm{~b}$ shows the first singular value $\left(\mathrm{SV}_{1}\right)$ lines obtained by applying the FDD technique to the vertical (blue curve, V) and lateral (red curve, L) signals collected in one dataset (dataset 1). The first three peaks in the $\mathrm{SV}_{1}$ lat. curve - corresponding to lateral modes $\mathrm{L}_{1}, \mathrm{~L}_{2}$ and $\mathrm{L}_{3}$ - are associated with smaller peaks in the $\mathrm{SV}_{1}$ vert. curve, that refers to the vertical direction. Conversely, the other local maxima (corresponding to modes $\mathrm{V}_{1}, \mathrm{~V}_{2}, \mathrm{~L}_{4}, \mathrm{~L}_{5}$ and $\mathrm{V}_{3}$ ) are associated with a unique dominant component of motion.

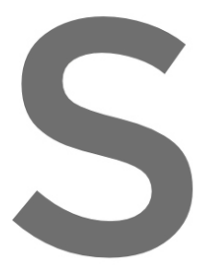

(a)

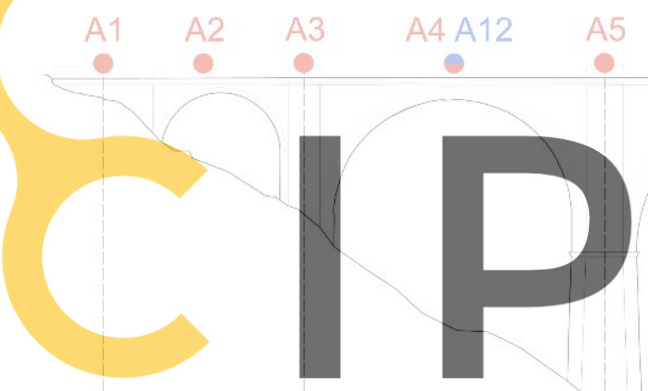

16.84
25.26

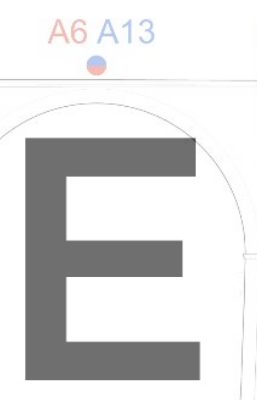

30.37

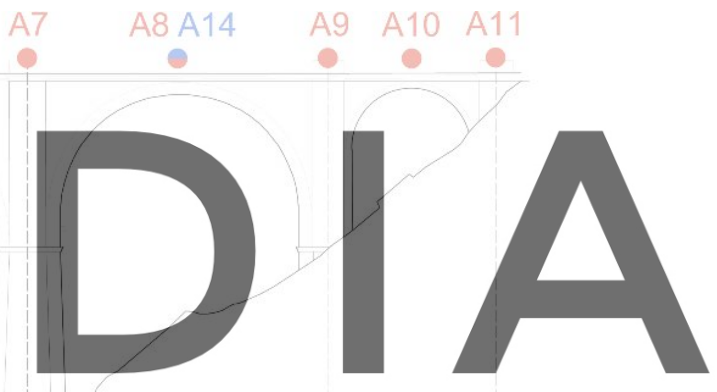

25.28
14.09

Register for free at https//www.scipedia.com to download the version without the watermark

- CUNEO

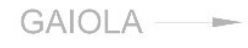

(b)

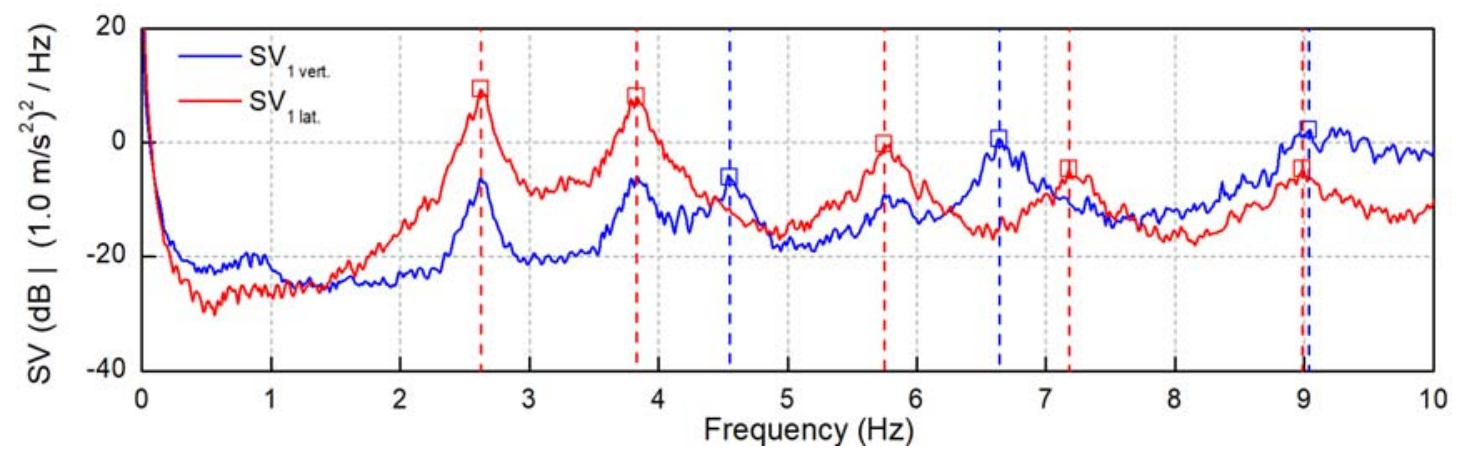

Figure 5: (a) Sensors layout during the AVT (dimensions in $\mathrm{m}$ ): the red and blue dots refer to transverse and vertical sensors, respectively; (b) Comparison between the first singular value lines of lateral ( $\left.\mathrm{SV}_{1 \text { lat. }}\right)$ and vertical $\left(\mathrm{SV}_{1 \text { vert. }}\right)$ responses and identification of modal frequencies (dataset 1$)$. 
The application of different output-only techniques (i.e. FDD, SSI-data and SSI-Cov) to the different datasets resulted in remarkably consistent natural frequencies and mode shapes, suggesting the invariance of the dynamic behaviour of the structure over the testing time. It is worth mentioning that during the test, the traffic on the open lane was quite intense. To exemplify the low variations of natural frequencies, the identification of lateral modes (SSICov) in four different datasets are reported in Tab. 1 and Fig. 6. Furthermore, the identified mode shapes are shown in Fig.7.

Table 1: Natural frequencies identified (SSI-Cov) in 4 different datasets (lateral modes).

\begin{tabular}{|c|c|c|c|c|c|c|c|}
\hline \multicolumn{2}{|c|}{ Mode } & \multicolumn{4}{|c|}{$f_{\text {SSI-Cov }}(\mathrm{Hz})$} & \multirow[b]{2}{*}{ Mean (Hz) } & \multirow[b]{2}{*}{ St. dev. (Hz) } \\
\hline No. & Type & Dataset 1 & Dataset 2 & Dataset 3 & Dataset 4 & & \\
\hline 1 & $\mathrm{~L}_{1}$ & 2.613 & 2.604 & 2.619 & 2.641 & 2.619 & 0.013 \\
\hline 2 & $\mathrm{~L}_{2}$ & 3.832 & 3.835 & 3.839 & 3.836 & 3.835 & 0.003 \\
\hline 4 & $\mathrm{~L}_{3}$ & 5.777 & 5.802 & 5.780 & 5.808 & 5.792 & 0.013 \\
\hline 6 & $\mathrm{~L}_{4}$ & 7.213 & 7.223 & 7.239 & 7.224 & 7.225 & 0.009 \\
\hline 7 & $\mathrm{~L}_{5}$ & 8.971 & - & 8.993 & 9.012 & 8.992 & 0.017 \\
\hline
\end{tabular}

(a) Dataset 1

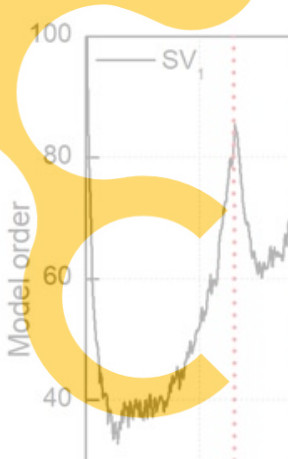

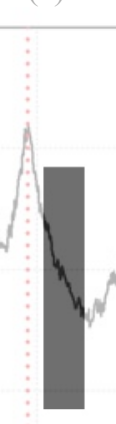

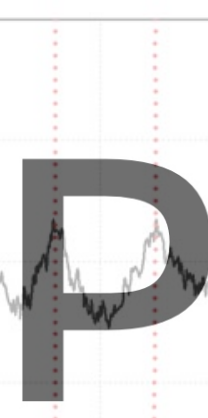

(b) Dataset 2

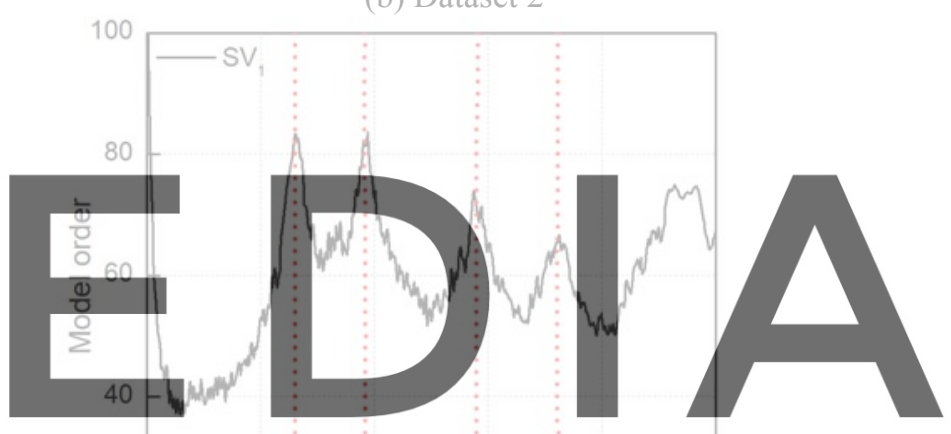

Register for free at https//www.scipedia.com to download the version without the watermark

(c) Dataset 3

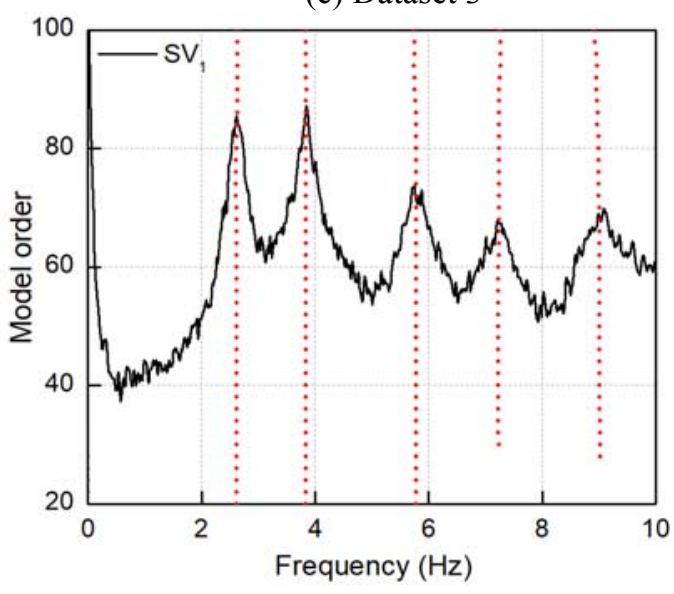

(d) Dataset 4

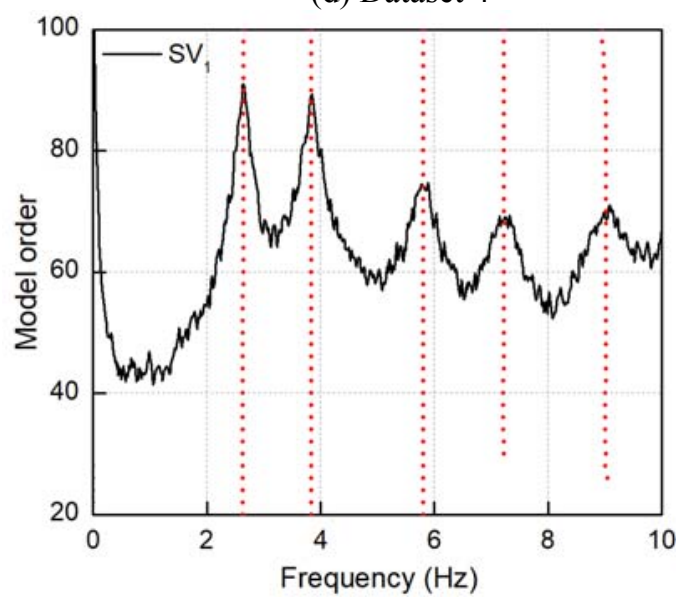

Figure 6: First singular values line (FDD) and alignments of stable poles (SSI-Cov) of different datasets: (a) dataset 1; (b) dataset 2; (c) dataset 3; (d) dataset 4 . 


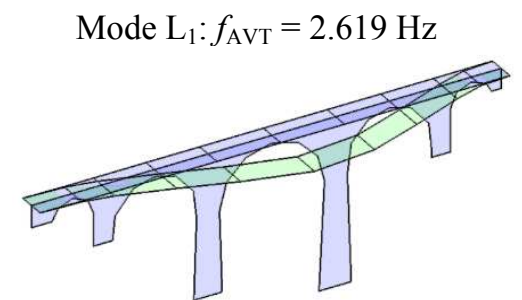

Mode $\mathrm{L}_{3}: f_{\mathrm{AVT}}=5.792 \mathrm{~Hz}$

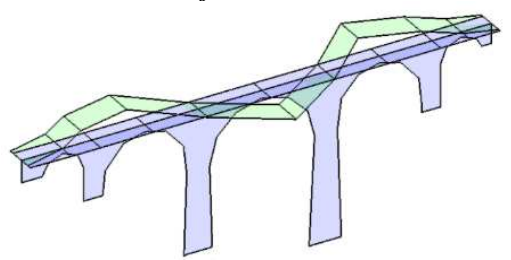

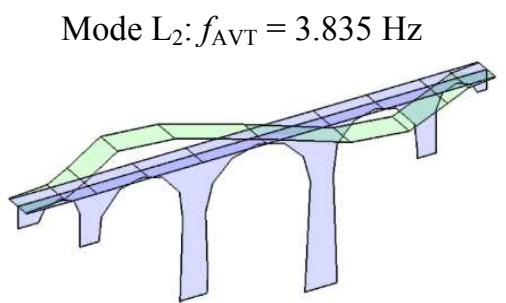

Mode $\mathrm{V}_{2}: f_{\mathrm{AVT}}=6.628 \mathrm{~Hz}$

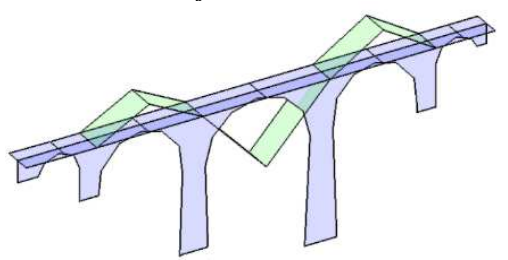

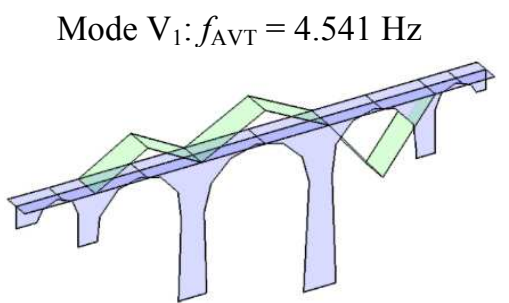

Mode $\mathrm{L}_{4}: f_{\mathrm{AVT}}=7.225 \mathrm{~Hz}$

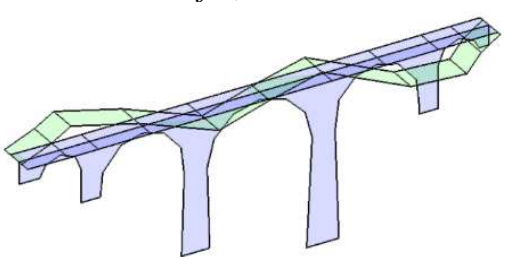

Mode $\mathrm{L}_{5}: f_{\mathrm{AVT}}=8.992 \mathrm{~Hz}$

Mode $\mathrm{V}_{3}: f_{\mathrm{AVT}}=9.033 \mathrm{~Hz}$

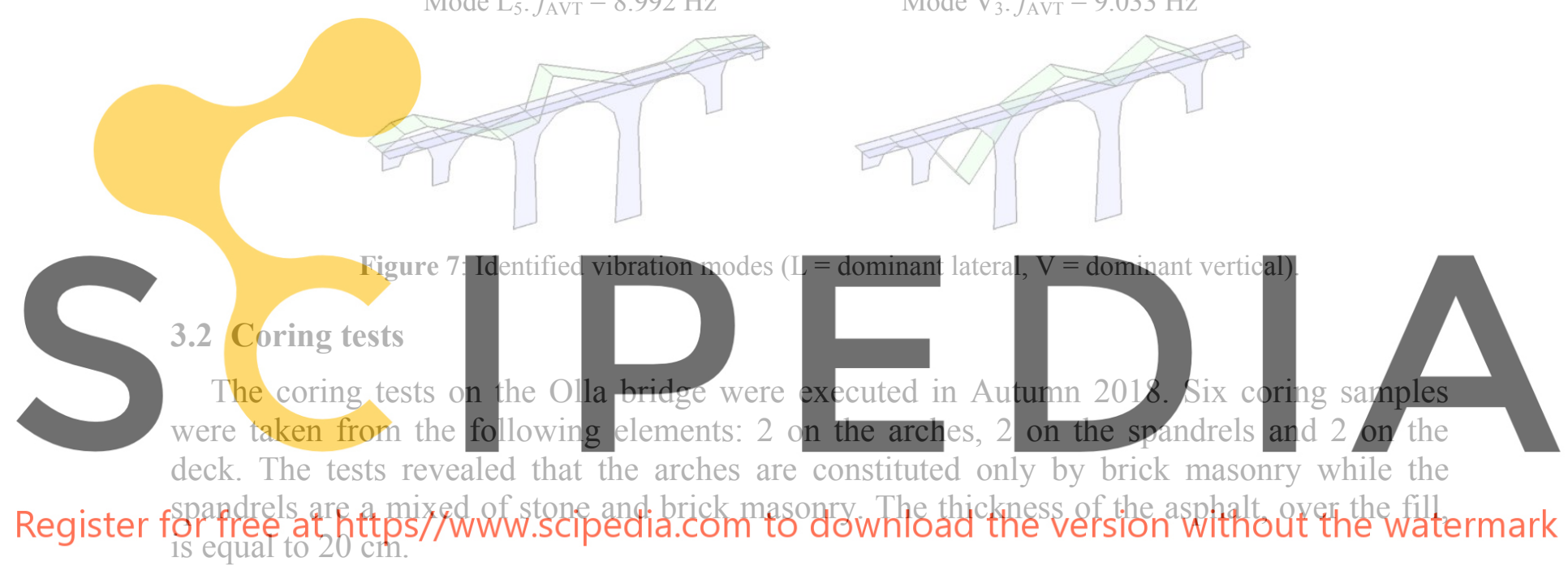

\section{FINITE ELEMENT MODELLING AND UPDATING}

The structural contribution of spandrels and backing is often not clear and hard to determine. Therefore, the standard approach in modelling masonry bridges considers the arches as the main load-bearing structure [1], neglecting the role of the other parts that form the deck (spandrels, backing and fill).

In a previous study [13], a simplified model was developed for the Olla bridge to clarify the contribution of non-structural components in the bridge dynamic response under operational conditions. The simplified model emphasised the importance of considering the stiffening effect given by the elements above the arch. Nevertheless, due to the simplified nature of the model it was impossible to match both lateral and vertical response. Consequently, the three-dimensional FE model herein presented reproduces as closely as possible the actual geometry of the bridge. Therefore, the spandrel walls, backing and fill have been modelled along with arches, abutments and piers; the material properties of each structural element are updated according to the adopted system identification procedure and a perfect connection between the different components is assumed. 


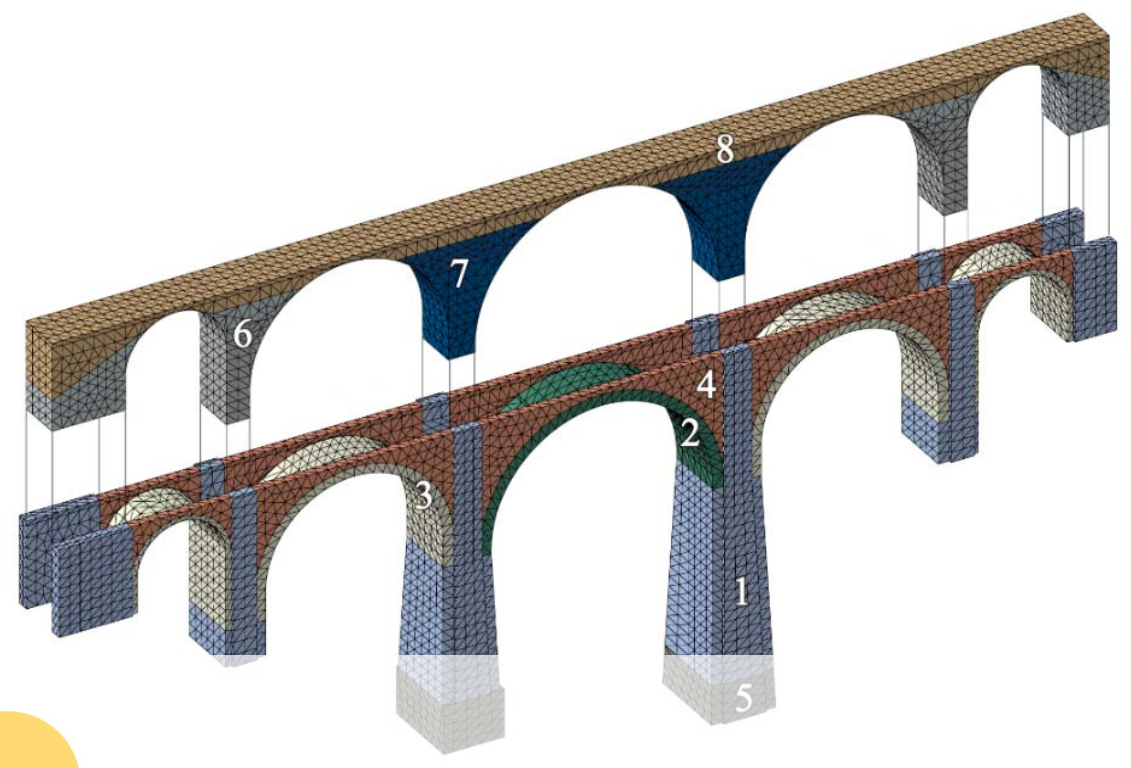

1) piers/abutments
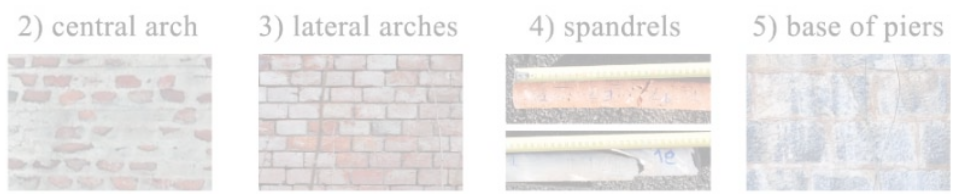

8) fill
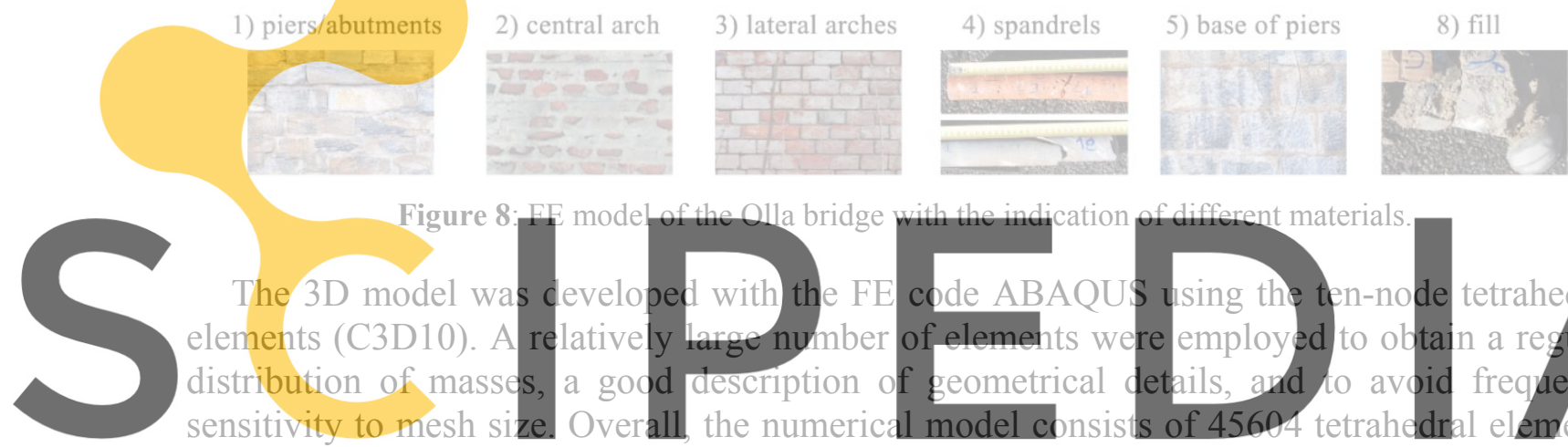

\section{Figure 8:}

The 3D model was developed with the FE code ABAQUS
elements (C3D10). A relatively large number of elements were

distribution of masses,

sensitivity to mesh size. Overall.

the numerica
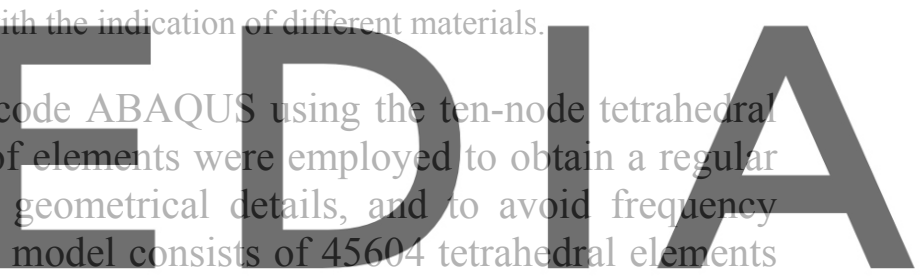

with 211818 degrees of freedom and an average mesh size of $1.15 \mathrm{~m}$ (Fig. 8).

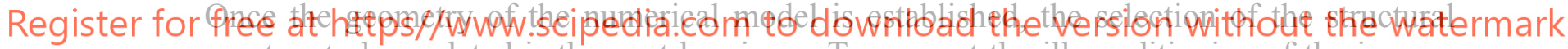
parameters to be updated is the next key issue. To prevent the ill-conditioning of the inverse problem and to improve the robustness of the updated parameter estimates, the following aspects were considered: (i) the number of updating variables was kept smaller than the experimental parameters used as targets; (ii) only the uncertain structural parameters were updated; (iii) the sensitivity of natural frequencies to the different parameters was checked and low-sensitivity structural parameters were not updated.

Overall, 8 regions with constant material properties were identified based on visual inspections and coring tests (Fig. 8): (1) piers and abutments; (2) the central arch (reconstructed in 1945); (3) lateral arches; (4) spandrels; (5) base of central piers; (6) backing over the abutments and the lateral piers; (7) backing over the central piers (partially reconstructed in 1945); (8) fill.

In addition, the following assumption were adopted: (a) the effect of soil-structure interaction was neglected, (b) all the materials were considered isotropic with constant mass density and Poisson's ratio (see Tab. 2), (c) the spandrels were assumed $1.0 \mathrm{~m}$ thick, and (d) the Young's modulus of fill material was not adjusted due to its low sensitivity. In view of the clear presence of superficial rocks at the river level, the base nodes of piers and abutments were assumed pinned. Similarly, the longitudinal translation of the abutments was restrained. 


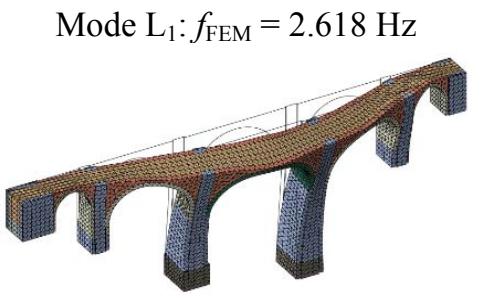

Mode $\mathrm{L}_{3}: f_{\mathrm{FEM}}=5.780 \mathrm{~Hz}$

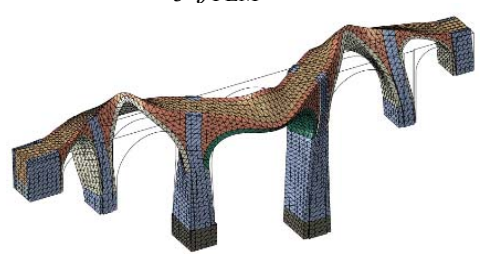

Mode $\mathrm{L}_{2}: f_{\mathrm{FEM}}=3.834 \mathrm{~Hz}$

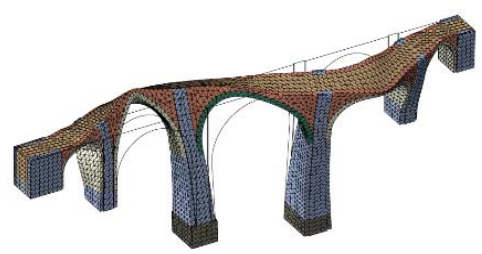

Mode $\mathrm{V}_{2}: f_{\text {FEM }}=6.625 \mathrm{~Hz}$

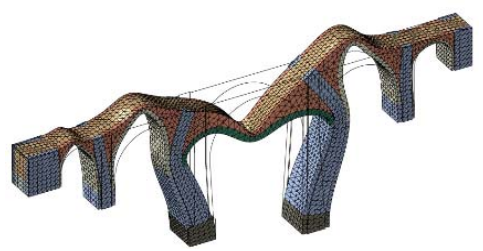

Mode $\mathrm{V}_{1}: f_{\mathrm{FEM}}=4.540 \mathrm{~Hz}$

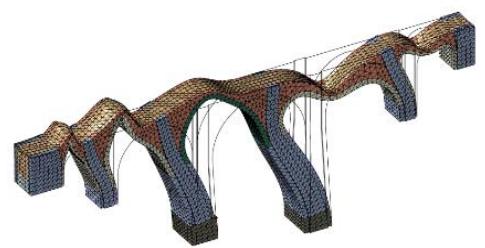

Mode $\mathrm{L}_{4}: f_{\mathrm{FEM}}=7.218 \mathrm{~Hz}$

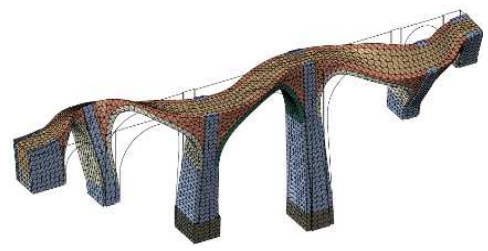

Mode $\mathrm{L}_{5}: f_{\mathrm{FEM}}=8.997 \mathrm{~Hz}$

Mode $\mathrm{V}_{3}: f_{\mathrm{FEM}}=9.088 \mathrm{~Hz}$
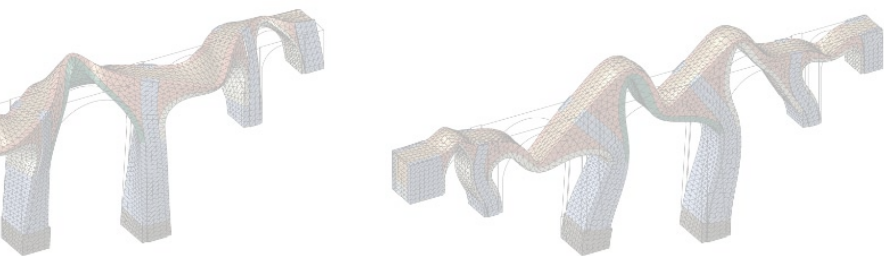

Figure 9: Lateral (L) and vertical (V) vibration modes of the optimal (updated) FE model.
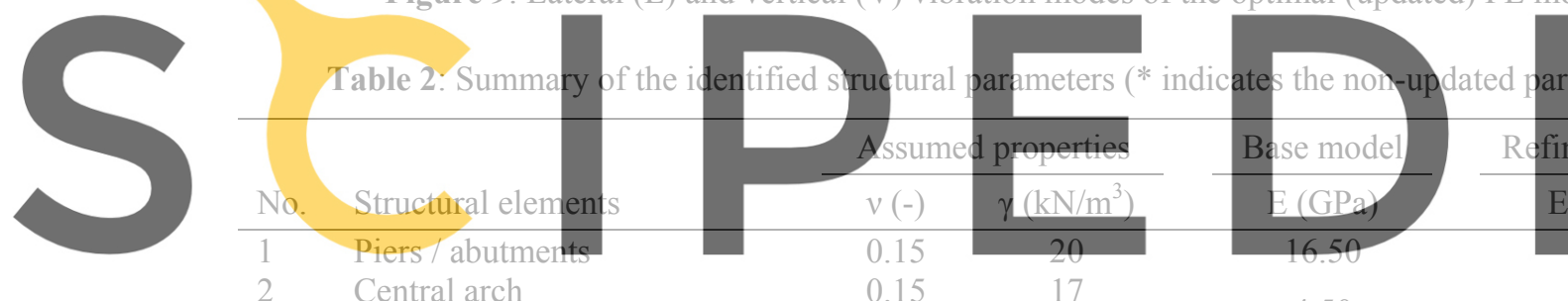

0.15

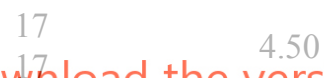

4.50 .

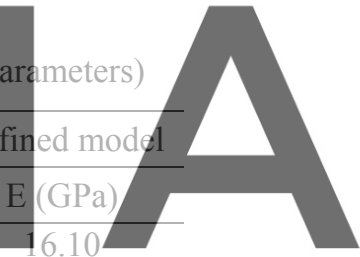

Pree a

5 Base of central piers

$6 \quad$ Backing lateral piers / abut.

Backing central piers

$8 \quad$ Fill *

7.73

version without the watermark

0.15

0.15

0.15

0.3
22.00

2.00

0.30
27.49

1.38

4.56

0.30

Table 3: Comparison between experimental (SSI-Cov) and numerical frequencies.

\begin{tabular}{|c|c|c|c|c|c|c|}
\hline \multicolumn{2}{|r|}{ Mode } & \multirow{2}{*}{$\frac{\text { Exp. (SSI-Cov) }}{f_{\text {AVT }}(\mathrm{Hz})}$} & \multicolumn{2}{|c|}{ Base model } & \multicolumn{2}{|c|}{ Updated model } \\
\hline No. & Type & & $f_{\text {FEM }}(\mathrm{Hz})$ & DF (\%) & $f_{\mathrm{FEM}}(\mathrm{Hz})$ & DF (\%) \\
\hline 1 & $\mathrm{~L}_{1}$ & 2.619 & 2.56 & 2.2 & 2.621 & -0.07 \\
\hline 2 & $\mathrm{~L}_{2}$ & 3.835 & 3.83 & 0.3 & 3.828 & 0.18 \\
\hline 3 & $\mathrm{~V}_{1}$ & 4.541 & 4.53 & 0.2 & 4.541 & -0.01 \\
\hline 4 & $\mathrm{~L}_{3}$ & 5.792 & 5.80 & -0.2 & 5.793 & -0.02 \\
\hline 5 & $\mathrm{~V}_{2}$ & 6.628 & 6.14 & 7.4 & 6.629 & -0.02 \\
\hline 6 & $\mathrm{~L}_{4}$ & 7.225 & 7.45 & -3.2 & 7.225 & -0.01 \\
\hline 7 & $\mathrm{~L}_{5}$ & 8.992 & 9.17 & -2.0 & 9.044 & -0.57 \\
\hline 8 & $\mathrm{~V}_{3}$ & 9.033 & 8.64 & 4.3 & 9.062 & -0.32 \\
\hline & $D F_{\text {ave }}(\%)$ & - & - & 2.46 & - & 0.15 \\
\hline & $D F_{\max }(\%)$ & - & - & 7.35 & - & 0.57 \\
\hline
\end{tabular}


An initial FE model (Base model) was developed to check the similarity between experimental and numerical modal parameters. As shown in Tab. 2, the Young's modulus of arches and backing was assumed equal to $4.5 \mathrm{GPa}$ and $2.0 \mathrm{GPa}$ respectively. Tab. 3 illustrates the imperfect correlation with the experimental results, showing a maximum frequency discrepancy $(D F)$ of $7.4 \%$. However, the one-to-one correspondence of the experimentalnumerical modes seems to provide a sufficient verification to the main model assumptions.

The adopted FEMU procedure was implemented in MATLAB environment and it is based on the Douglas-Reid method [14] with the Particle Swarm Optimisation (PSO) algorithm: the updating parameters are iteratively corrected in a constrained range until a stable minimum solution for an objective function is found. Particularly, the following objective function was adopted:

$$
J(\boldsymbol{x})=\frac{100}{n} \sum_{i=1}^{n}\left|\frac{f_{i}^{A V T}-\hat{f}_{i}(\boldsymbol{x})}{f_{i}^{A V T}}\right|
$$

where $f_{\mathrm{i}}^{\mathrm{AVT}}$ are the i-th experimentally identified natural frequency and $f_{\mathrm{i}}(\boldsymbol{x})$ are the $i$-th polynomial approximations [14] of the numerical natural frequencies, expressed as functions of the $\boldsymbol{x}$ updating parameters.

Tab. 2 lists the optimal estimates of the uncertain parameters of the model. The differences between the elastic moduli of the central and lateral arches, as well as the one of the backing, are motivated by the different years of construction: as shown by the historical analysis, the central arch was rebuilt in 1945. As demonstrated by the coring tests, the spandrels are made of bricks externally and stone internally, justifying the high values elastic modulus obtained. Finally, the base of the central piers is built in a better-quality stone masonry in respect to the rest of the piers and, moreover, the optimal elastic modulus conceivably accounts for the stiffening effect provided by the compacted soils surrounding the piers.

\section{CONCLUSIONS}

The paper focuses on the OMA-based structural identification based of the Olla bridge of Gaiola, Piedmont region, northwest Italy. The occasional brick fall from one of the arches had caused concerns on the state of preservation of the structure by the local Authorities, motivating the following research programme. The investigations included documentary research, geometric survey, minor destructive and ambient vibration testing, and FE modelling and updating. The following conclusions can be drawn:

1) The documentary research revealed the construction period and designer, along with a series of historical pictures of the collapsed central arch in 1944;

2) During the AVT, performed with one line open to traffic, 5 lateral and 3 vertical vibration modes were identified in the frequency range of $0-10 \mathrm{~Hz}$;

3) Notwithstanding the initial model represented accurately the geometry retrieved from geomatic survey, a relatively poor correlation with the actual structural response was obtained $\left(D F_{\text {ave }}=2.46 \%, D F_{\max }=7.35 \%\right)$;

4) On the contrary, as shown in Fig. 9, applying the developed FEMU procedure and considering the effects of the reconstruction of 1945, an excellent correlation with the experimental results was obtained $\left(D F_{\text {ave }}=0.15 \%, D F_{\max }=0.57 \%\right)$, highlighting the importance of backing and spandrels in the dynamic response of masonry bridges. 
To complete the structural assessment of the Olla bridge, a full-scale load tests and additional minor-destructive and non-destructive tests on materials should be performed in near future.

Acknowledgements. The support of ANAS (Struttura territoriale Piemonte e Valle d'Aosta) is gratefully acknowledge. Sincere thanks are due to M. Cucchi and M. Iscandri (LPMSC, Politecnico di Milano) who assisted the authors in conducting the field tests.

\section{REFERENCES}

[1] Brencich, A. and Morbiducci, R. Masonry arches: Historical rules and modern mechanics. Int. J. Archit. Herit. (2007) 1(2):165-189.

[2] Costa, C., Ribeiro, D., Jorge, P., Silva, R., Arêde, A. and Calçada, R. Calibration of the numerical model of a stone masonry railway bridge based on experimentally identified modal parameters. Eng. Struct. (2016) 123:354-371.

[3] Scozzese, F., Ragni, L., Tubaldi, E. and Gara, F. Modal properties variation and collapse assessment of masonry arch bridges under scour action. Eng. Struct. (2019) 119:109665.

[4] Fassi, F. and Achille, C. Relazione delle attività di rilievo topografico e laser-scanner: Ponte dell'Olla località Gaiola (CN) (in Italian). Technical report, Politecnico di Milano (2018).

[5] Ministero dei lavori pubblici. Relazione sul mantenimento delle Strade Nazionali durante il periodo dal $1^{\circ}$ Luglio 1887 al 30 Giugno 1888 (in Italian). Tipografia Eredi Botta, Rome (1889).

[6] Taricco, S. Il tramvai di Demonte: ricordi di una storia passata (in Italian). Mauro Fantino Editore, Borgo San Dalmazzo (2001).

[7] Curioni, G. L'arte del costruire: costruzioni civili, stradali ed idrauliche (in Italian). Augusto Federico Negro Editore, Turin (1873).

[8] Giornale del Genio Civile. Tavole (in Italian). Istituto Poligrafico dello Stato, Roma (1879).

[9] Brincker, R., Zhang, L. and Andersen, P. Modal identification of output-only systems using frequency domain decomposition. Smart Mater. Struct. (2001) 10(3):441-445.

[10] Peeters, B. System identification and damage detection in civil engineering. Ph.D. Thesis, Katholieke Universiteit Leuven, Belgium (2000).

[11] Structural Vibration Solutions (SVS). ARTeMIS Extractor 2010. Aalborg, Denmark (2010).

[12] Cabboi, A., Magalhães, F., Gentile, C. and Cunha, A. Automated modal identification and tracking: Application to an iron arch bridge. Struct. Control Health Monit. (2017) 24(1): e1854.

[13] Borlenghi, P., Saisi, A. and Gentile, C. Preliminary Structural Assessment of a Multispan Masonry Arch Bridge. In: Arêde A. and Costa C. (Eds.): Proceedings of ARCH 2019, Structural Integrity 11 (2020). Springer, Cham.

[14] Douglas, B. M. and Reid, W. H. Dynamic tests and system identification of bridges. $J$. Struct. Div. ASCE (1982) 108(10):2295-2312. 